\title{
CUIDADOS DE ENFERMAGEM E O TESTE DO PEZINHO
}

\author{
[Nursing care and Neonatal Screening]
}

Marly B. Gervásio Marton da Silva*
Ivete Palmira Sanson Zagonel**
Maria Ribeiro Lacerda

RESUMO: Estudo realizado junto ao Serviço de Referência em Triagem Neonatal no Estado do Paraná (FEPE), objetivando identificar o índice de coletas de sangue inadequadas recebidas pelo laboratório da FEPE para realização do exame, no período de janeiro a dezembro de 2002. Foram estudadas fichas cadastrais dos registros internos do laboratório da FEPE e analisados 222.366 exames nos quais identificamos 2.787 com necessidade de repetição por erros nas coletas. Os critérios utilizados na classificação foram: transfusão de sangue, sangue insuficiente, hemolisado, envelhecido, excesso, contaminado e ressecado. Com base nos dados levantados e analisados, verificamos que os maiores índices de erros estão no sangue insuficiente e envelhecido, indicando dificuldades na execução da técnica de coleta, que podem estar relacionadas à falta de conhecimento técnico-científico e desvalorização do exame, às trocas de profissionais treinados por outros não qualificados e, à demora significativa no envio das amostras de sangue ao laboratório, realçando a falta de sensibilidade quanto à importância do exame.

PALAVRAS-CHAVE: Triagem neonatal; Controle de qualidade; Educação continuada em enfermagem; Enfermagem neonatal; Imperícia.

* Enfermeira da Fundação Ecumênica de Proteção ao Excepcional (FEPE). Especialista em Projetos Assistenciais de Enfermagem pela UFPR. Mestranda em Enfermagem (UFPR). Membro efetivo da Sociedade Brasileira de Triagem Neonatal (SBTN). Diretora de Divulgação da Associação de Fenilcetonúricos e Homocistinúricos do Paraná (AFEHPR). Membro do Núcleo de Estudo, Pesquisa e Extensão do Cuidado e de Enfermagem - NEPECHE / UFPR.

** Doutora em Filosofia de Enfermagem e Mestre em Assistência de Enfermagem pela UFSC. Membro e Pesquisadora do NEPECHE e docente dos cursos de graduação e pós-graduação de enfermagem da UFPR.

*** Doutora em Filosofia de Enfermagem e Mestre em Assistência de Enfermagem pela UFSC. Especialista em Metodologia do Ensino Superior pela UEL, Administração Hospitalar pela São Camilo e Assistência de Enfermagem pela Ana Néri. Membro e Pesquisadora do NEPECHE. Docente do curso de graduação e pós-graduação de enfermagem da UFPR.

\section{INTRODUÇÃO}

Toda criança que nasce traz em si a esperança, a alegria, a perspectiva de um mundo melhor e mais feliz. As pessoas ao redor, pais, familiares e amigos, renovam suas esperanças, depositam nesse novo ser todas as suas expectativas, buscando às vezes, suas próprias realizações.

A mulher quando gestante, anseia e espera pelo nascimento do filho, acreditando sempre que ele será saudável, imune às doenças que só os outros têm; porém, nem sempre o processo acontece de forma condizente com o que foi sonhado e o bebê nasce portador de alguma enfermidade que pode e deve ser diagnosticada e tratada precocemente, prevenindo assim seqüelas, permitindo a continuidade de uma vida saudável e com qualidade.

No Brasil, o Programa de Triagem Neonatal para fenilcetonúria existe desde 1976, o qual é realizado pela APAE/ SP, a precursora do teste do pezinho no Brasil, e foi ampliado em 1986, pesquisando também o hipotireoidismo congênito. No Paraná, com a Lei Estadual n. ${ }^{\circ} 8627$ (PARANÁ, 1987), existe a obrigatoriedade do exame para essas duas enfermidades desde 1987. Esse exame faz parte do Programa, o qual sempre foi realizado pela Fundação Ecumênica de Proteção ao Excepcional (FEPE), entidade filantrópica, não governamental, com sede em Curitiba, e credenciada junto ao Ministério da Saúde como o Serviço de Referência em Triagem Neonatal (SRTN) no Estado do Paraná.

Atualmente, o Programa Nacional de Triagem Neonatal (PNTN), criado e implementado pela Portaria Ministerial $n^{\circ}$ 822/01 (BRASIL, 2001), possibilita a pesquisa gratuita e obrigatória de várias doenças como a fenilcetonúria, o hipotireoidismo congênito, as hemoglobinopatias e a fibrose cística ou mucoviscidose. No Estado do Paraná, através da FEPE, pesquisa-se também, além das citadas, a Deficiência da Biotinidase.

Trata-se de um Programa porque todos os bebês, com diagnóstico positivo para alguma das doenças pesquisadas, recebem tratamento especializado da equipe interdisciplinar do Centro de Pesquisas da FEPE, em ambulatórios do 
Hospital de Clínicas, devido a um convênio existente entre a FEPE e a Universidade Federal do Paraná.

Para que o Programa tenha êxito, atingindo o seu maior objetivo que é a prevenção das seqüelas, faz-se necessário um trabalho de base, ou seja, em um primeiro momento, a enfermagem interagindo com as futuras mães ainda no pré-natal, com os familiares e até com as comunidades, informando sobre a importância do teste do pezinho, através da conscientização, da sensibilização. MAZZA (1998), vem corroborar ao referir que o desenvolvimento da enfermagem acontece a partir da interação entre os seres humanos, principalmente nos momentos mais difíceis de dor, conflito ou crise.

Consideramos que no momento da coleta de sangue para o teste do pezinho, é muito importante que a mãe segure o filho no colo, pois assim o bebê se sentirá protegido pelo abraço da mãe, ela sentir-se-á mais potente em proteger o filho e a própria coleta ocorrerá de forma mais rápida e eficaz, porque com o bebê em pé, o sangue concentra-se mais no pezinho e a qualidade da coleta também melhora. Essa interação proporciona ainda uma educação em saúde quanto ao exame, tirando da mãe e até dos familiares e/ou amigos, eventuais receios que possam existir em relação à coleta.

A promoção do ensino-aprendizagem na relação interpessoal enfermeira e cliente é o fator que proporciona às pessoas o máximo de controle sobre sua própria saúde, por receberem informações e alternativas. A enfermeira focaliza o processo de aprendizagem e o processo de ensino, uma vez que a aprendizagem propicia o melhor caminho de individualização da informação a ser disseminada. A compreensão das percepções que a pessoa tem da situação ajuda a enfermeira a preparar um plano cognitivo que trabalha a sensibilidade da pessoa, aliviando o estresse do acontecimento.

No segundo momento, existe a importância da correta execução da técnica de coleta de amostras de sangue em papel filtro, por punção cutânea do calcanhar do bebê, cuja responsabilidade fica quase que inteiramente para a equipe de enfermagem dos hospitais/maternidades e unidades básicas de saúde.

A enfermagem como conjunto de ações interativas entre pessoas, visando o bem estar do outro em toda a sua complexidade, através de atitudes humanizadas de prevenção, cuidado e educação, pode, por ações simples e rotineiras como a coleta de sangue para o teste do pezinho, ajudar crianças portadoras de doenças congênitas a atingirem um futuro mais promissor, evitando que seu desenvolvimento normal seja interrompido ou retardado (MARTON DA SILVA, 2002).
Quando uma amostra de sangue para o teste do pezinho é coletada sem a qualidade exigida, ou seja, considerada uma má coleta, a mãe é reconvocada para repetir o exame do seu bebê o mais urgente possível, pelo serviço social do Centro de Pesquisas da FEPE, o que provoca desconforto e estresse à família, atraso no diagnóstico e início tardio do tratamento nos casos positivos para alguma das doenças pesquisadas, principalmente se houver dificuldade em localizar essa mãe e seu bebê.

MARTON DA SILVA (2002) refere que a perda de um caso positivo para os profissionais que trabalham no Programa, representa não poder fazer o acompanhamento de uma criança que nasceu sem manifestações clínicas, mas portadora de uma doença sem cura, embora com possibilidades de evitar o surgimento do quadro clínico para que possa ter uma expectativa de qualidade de vida como a de qualquer outra criança. A inadequação da amostra de sangue gera também um custo operacional para a FEPE, devido às despesas com material enviado para os postos de coletas cadastrados no Programa.

Vários são os fatores que interferem na qualidade do cuidado de enfermagem na execução da técnica de coleta do sangue para o teste do pezinho. Segundo MARTON DA SILVA (2002), a posição do bebê que deve estar preferencialmente em pé, no colo da mãe; a necessidade do aquecimento prévio do pezinho do bebê para que haja uma concentração maior do sangue; a importância de não apertar demasiado o pé do recém-nascido, evitando a hemólise; desprezar sempre a primeira porção de sangue; preencher totalmente com sangue os círculos do papel filtro; e outros, que devem ser conhecidos e observados pelos profissionais de enfermagem no momento da coleta.

É também muito importante que o profissional se coloque no lugar da mãe e principalmente do bebê, procurando desenvolver a técnica sempre preocupado com um cuidado humanizado, visando o bem estar e o conforto do cliente e não o que é mais fácil e mais cômodo para si, ou seja, nunca apertar a perna nem o pé do bebê, nunca girar a lanceta quando puncionar o calcanhar do bebê, observar o local adequado para a punção. "Através do exercício da empatia, com certeza, seremos melhores profissionais, melhores pessoas" (MARTON DA SILVA, 2002, p.3).

Todas essas razões levam-nos à reflexão, como profissional enfermeira do Programa Nacional de Triagem Neonatal no Paraná, sobre a necessidade de informar, conscientizar, sensibilizar, fornecer conhecimento técnicocientífico sobre as enfermidades pesquisadas no teste do pezinho e as seqüelas irreversíveis quando não diagnosticadas e tratadas precocemente e, provocar nos profissionais de saúde, principalmente da enfermagem, uma 
reflexão profunda sobre a importância e responsabilidade do seu papel na prevenção.

O exame é gratuito e obrigatório, então, todos os bebês, indistintamente, têm direitos, como cidadãos que são, à prevenção do retardo mental e outros comprometimentos, fornecidos pelo PNTN. Para que haja eficácia nesta prevenção, é extremamente importante que as amostras de sangue sejam coletadas corretamente, por isso buscamos identificar e analisar os erros apresentados nas coletas.

\section{CONHECENDO A DINÂMICA DE TRABALHO DO PNTN NO PARANÁ}

Para o Programa Nacional de Triagem Neonatal (PNTN) no Estado do Paraná, a realização da coleta de sangue em papel filtro deve acontecer sempre na alta hospitalar do bebê e da mãe, e o ideal com 48 horas de vida do recém-nascido. Quando a alta hospitalar acontece com 48 horas ou mais é feita uma coleta, porém quando ocorre antes das 48 horas, a coleta do sangue é feita na alta, independente do tempo de vida do bebê, e a mãe é orientada a repeti-la dentro de uma semana, na unidade de saúde mais próxima de sua casa ou na maternidade onde nasceu seu filho.

Esta rotina justifica-se devido ao resultado falso normal ou falso negativo para fenilcetonúria caso o bebê ainda não tenha mamado leite suficiente e, também, para garantir a realização do exame precoce caso a mãe, por algum motivo, não comparecer a um posto de coleta ou até mesmo, demorar muitos dias para fazê-lo, podendo comprometer o diagnóstico e tratamento precoces, na situação em que o bebê seja positivo para uma das doenças pesquisadas.

O Paraná possui 399 municípios, mas nem todos têm hospitais, ficando assim, a responsabilidade da coleta nesses municípios, para as unidades básicas de saúde. Apesar de existir uma Recomendação do Conselho Estadual de Saúde, alguns municípios ainda não realizam o teste do pezinho em suas unidades de saúde, mas a FEPE atua intensificando contatos com os Conselhos Municipais e locais de Saúde e Conselhos Tutelares, para que auxiliem no controle social, cobrando das autoridades locais uma postura ética e responsável para implantar a coleta nesses serviços de saúde.

Todos os bebês cujos exames para o teste do pezinho apresentam resultados alterados ou com erros na coleta do sangue são reconvocados imediatamente para repetição da coleta, através de busca realizada pela equipe do serviço social do laboratório da FEPE, com telefonemas e cartas às mães e às instituições onde aconteceram as coletas.

Quando o exame repetido apresenta resultado positivo para alguma das doenças pesquisadas, as assistentes sociais localizam as mães e seus filhos onde quer que residam no estado do Paraná e, trazem-nos para consulta no ambulatório especializado em parceria com o Hospital de Clínicas em Curitiba, iniciando assim o tratamento indicado e acompanhamento pela equipe interdisciplinar da FEPE constituída por médicos, nutricionista, assistentes sociais, enfermeira e psicóloga. Como os tratamentos para as enfermidades pesquisadas no teste do pezinho devem durar a vida toda, o Programa prevê para as crianças portadoras de tais doenças, o acompanhamento com a equipe multidisciplinar especializada do Centro de Pesquisas da FEPE.

Para garantir a continuidade de ações e serviços preventivos de maneira a oferecer uma assistência integral, conforme preconiza o princípio II da Lei Federal n. ${ }^{\circ} 8080$ de 19 de setembro de 1990 (BRASIL, 1990), a FEPE mantém articulação com outros serviços, como por exemplo, a Associação dos Fenilcetonúricos e Homocistinúricos do Paraná (AFEH-Pr), visando proporcionar maior qualidade e eficácia ao tratamento.

\section{A ENFERMEIRA ATUANDO DIRETAMENTE NO PNTN DO PARANÁ}

O serviço de enfermagem do Centro de Referência em Triagem Neonatal do Paraná, FEPE, conta com uma enfermeira desde 1997, atuando principalmente na divulgação e promoção da adequada qualidade na técnica de coleta do teste do pezinho a todas as entidades participantes do Programa no estado.

Dentre as várias atividades realizadas por essa profissional estão: o controle semanal das ocorrências de más coletas através do sistema Intranet do Centro de Pesquisas da FEPE; contatos telefônicos com as equipes de enfermagem dos hospitais e unidades de saúde onde incidem as más coletas, para orientação e esclarecimentos de dúvidas quanto à técnica de coleta do teste do pezinho; envio de cartas às gerências de enfermagem dos postos de coletas (hospitais e unidades de saúde), informando a ocorrência de erros na execução da técnica, orientando sobre como evitá-los e solicitando que haja maior treinamento para a equipe de enfermagem envolvida com o teste do pezinho.

Realiza também visitas pessoais às maternidades, secretarias municipais de saúde e unidades básicas de saúde do estado do Paraná, realizando reuniões, palestras e treinamentos aos enfermeiros e suas equipes; aulas teóricopráticas nas escolas de enfermagem de Curitiba e demais municípios visitados, nos três níveis: superior, técnico e auxiliar; verifica se todos os hospitais coletam o sangue para o teste do pezinho na alta hospitalar, conforme obriga a lei; 
verifica quais municípios do Paraná ainda não participam do Programa; verifica quais municípios não possuem hospitais e/ou maternidades.

Outras responsabilidades da enfermeira do PNTN da FEPE são: identificar os enfermeiros responsáveis pelo serviço de enfermagem dos hospitais e unidades de saúde; contatar os secretários municipais de saúde através de telefonemas, cartas e/ou visitas pessoais, para adesão dos seus municípios ao Programa; manter contatos telefônicos e/ou pessoais com conselhos tutelares, pastorais da criança e agentes comunitários de saúde, informando e orientando sobre a importância e necessidade do teste do pezinho, solicitando-Ihes cooperação na divulgação e na busca ativa das mães dos bebês que requerem repetição da coleta de sangue para novo exame.

\section{A CAMINHADA PELO PNTN DO PARANÁ}

O serviço de enfermagem do Centro de Pesquisas da FEPE estudou as fichas cadastrais dos registros internos do laboratório, das coletas de 222.366 amostras de sangue para o teste do pezinho no período de janeiro a dezembro de 2002, realizadas em 467 hospitais/maternidades e 600 unidades de saúde no estado do Paraná cadastrados na FEPE, para identificação e análise dos tipos de erros de coleta.

As fichas com as amostras de sangue em papel filtro, que após as análises pelas bioquímicas do laboratório, apresentam resultados normais são arquivadas nas dependências da FEPE; já as que demonstram erros na coleta do sangue ou apresentam resultado alterado, são reconvocadas pelo Serviço Social da FEPE, para repetir a coleta.

Para classificação dos tipos de erros de coleta, a FEPE utiliza critérios e código numérico individual interno para a sua identificação (MARTON DA SILVA, 1999), conforme apresentamos a seguir: 993 (transfusão de sangue): se há indicação para transfusão sangüínea, a coleta para o teste do pezinho deve ocorrer sempre antes do procedimento indicado; 994 (sangue contaminado ou comprometido): quando as amostras de sangue são colocadas em local onde há manipulação de líquidos (pias, lavatórios, salas de esterilização, etc.). Atentar também para que não haja insetos no local onde aguarda a secagem do sangue das amostras. Evitar a preservação das amostras de sangue em pacote fechado por vários dias; 995 (sangue envelhecido): quando a amostra de sangue demora mais de trinta dias, após a coleta, para dar entrada no laboratório. Isto impossibilita a realização da análise pelo laboratório e pode comprometer o bebê, caso seja positivo para alguma das doenças pesquisadas pelo teste do pezinho. Enviar os exames ao laboratório, no mínimo, duas vezes por semana; 996 (sangue em excesso): quando pinga gota sobre gota e não movimenta o papel filtro para ajudar a espalhar o sangue. Há sobreposição das gotas de sangue, provocando excesso de sangue num só local; 997 (sangue hemolisado): o sangue aparenta aspecto de diluição no conjunto ou nas bordas. Provavelmente, quando há contato da amostra coletada com algum líquido (soro, água, etc.) ou quando há mistura do álcool da anti-sepsia com a gota de sangue no momento da coleta. Pode ocorrer também quando comprime demais o calcanhar do bebê, próximo ao local da punção; 998 (sangue ressecado): quando o material coletado fica exposto ao calor ou ao frio em excesso. Cuidar com o armazenamento, deixar os exames em local arejado, enquanto aguarda os dias de envio ao laboratório; 999 (sangue insuficiente): quando os círculos não são preenchidos completamente ou há sangue só de um lado do papel. Isto ocorre quando não há formação da gota para pingar no papel, principalmente se a coleta não acontece com o bebê em pé, no colo da mãe.

\section{ANALISANDO E DISCUTINDO OS DADOS OBTIDOS}

Das 222.366 amostras de sangue coletadas em papel filtro para o teste do pezinho, recebidas pela FEPE, procedentes de hospitais/maternidades e unidades básicas de saúde do Paraná, foi identificado um total de 2.787 amostras com erros na coleta, correspondendo a $1,25 \%$ de todos os exames realizados no período de janeiro a dezembro de 2002. Ressalvamos que o número de exames coletados não corresponde ao número de nascidos vivos no Estado, devido às repetições de coletas de amostras de sangue. Os números de exames reconvocados por tipos de erros nas coletas de sangue para o teste do pezinho, no período de janeiro a dezembro de 2002, foram: 7 exames por sangue em excesso; 165 exames por transfusão de sangue; 186 exames por sangue comprometido/contaminado; 241 exames por sangue hemolisado; 490 exames por sangue ressecado; 500 exames por sangue envelhecido e 1.198 exames por sangue insuficiente.

Com base nos achados, podemos verificar que o maior índice de erros apontou para a insuficiência de sangue, perfazendo $43 \%$ do total das más coletas no período analisado de janeiro a dezembro de 2002, seguido pelo sangue envelhecido que representou $18 \%$. Estes dados encontrados demonstram que existem dificuldades na execução da técnica de coleta de sangue capilar por punção cutânea, principalmente no momento da punção, que podem estar relacionadas às trocas de profissionais treinados por outros não qualificados e também ao sentimento de "dó" ao terem que "furar" o pé do bebê. Constatamos também, que 
existe uma demora muito significativa no envio das amostras de sangue para o laboratório, contando a partir da data da coleta, o que nos faz pensar que os profissionais de enfermagem ainda não estão totalmente sensibilizados e conscientizados quanto ao grande valor do teste do pezinho para todos os recém-nascidos.

\section{CONSIDERAÇÕES FINAIS}

Desta forma, consideramos a educação continuada em saúde para o teste do pezinho uma necessidade para a qualidade do cuidado de enfermagem, através de cursos periódicos de atualização, sensibilização, conscientização e reforço dos conhecimentos técnico-científicos do teste do pezinho, contribuindo, assim, para a diminuição da prevalência dos exames reconvocados por erros na técnica de coleta, objetivando, principalmente, a prevenção efetiva de seqüelas das doenças triadas no Programa Nacional de Triagem Neonatal.

Vimos desenvolvendo nosso trabalho junto ao PNTN no Paraná há seis anos, realizando palestras, ministrando cursos, treinando os profissionais quanto à técnica correta da coleta de sangue para o exame, buscamos sensibilizar as pessoas, mas parece-nos que a responsabilidade pela efetividade da prevenção não está sendo compartilhada pelos demais profissionais enfermeiros que atuam na neonatologia dos hospitais/maternidades e das unidades de saúde. Ainda não se deram conta de como e quanto é importante o teste do pezinho. Se há troca ou férias de pessoal do setor, por que não existe o cuidado de orientar e treinar o novo elemento para desempenhar a função de coletar o sangue?

Todo esse trabalho voltado para a qualidade do cuidado da enfermagem ao realizar o teste do pezinho visa, principalmente, o cliente, o recém-nascido e também sua mãe.

Quando deparo com crianças que foram diagnosticadas pela triagem neonatal e iniciaram o tratamento específico precocemente e, por isto, continuam pessoas saudáveis, "normais", alegres, inteligentes, lindas, um sentimento enorme de felicidade, de satisfação, de missão cumprida invade todo meu ser, pois sei que através do trabalho desenvolvido pela FEPE e tantos outros Serviços de Referência em Triagem Neonatal no mundo, e principalmente que pela atuação responsável das equipes de enfermagem dos serviços de neonatologia dos hospitais/maternidades e unidades de saúde, "vidas foram salvas".

ABSTRACT: This paper deals with a study undertaken at the Paraná Neonatal Screening Reference Service (FEPE), the aim of which was identifying the level of inadequate blood samples received by the FEPE laboratory for testing from
January to December 2002. A study was made of the FEPE Laboratory's internal medical records and 222,366 tests were examined, of which we identified 2,787 as needing to be repeated due to mistakes made during sample collection. The criteria used for classification were as follows: blood transfusion, insufficient, haemolysed, old, excess, contaminated and dried blood. Based on the data obtained and analysed, we were able to determine that the greatest amount of errors relate to insufficient and old blood, indicating difficulties in carrying out the collection technique, which may relate to: the lack of technical and scientific knowledge and the undervaluing of the importance of the test, the replacement of trained staff by untrained staff and the significant delay in sending the blood samples to the laboratory, emphasising the lack of awareness as to the test's importance.

KEY WORDS: Neonatal screening; Quality control; Education nursing continuing; Neonatal nursing; Malpractice.

\section{REFERÊNCIAS}

1 BRASIL. Lei Federal n. ${ }^{\circ} 8080$ de 19 de setembro de 1990 Regulamenta em todo o território nacional as ações de serviço de saúde. Brasília, 1990.

2 BRASIL. Portaria GM/MS n. ${ }^{\circ} 822$ I GM em 6 de junho de 2001. Instituição do Programa Nacional de Triagem Neonatal, no âmbito do Sistema Único de Saúde, para fenilcetonúria, hipotireoidismo congênito fibrose cística e hemoglobinopatias - Brasília: Ministério da Saúde, 2001.

3 MARTON DA SILVA, M.B.G. Manual da técnica de coleta de sangue para o teste do pezinho - mimeografado. Curitiba, 1999.

4 MARTON DA SILVA, M.B.G. Programa de educação continuada a distância na triagem neonatal. Monografia (Especialização em Projetos Assistenciais de Enfermagem). Curso de Pós-Graduação em Enfermagem, Universidade Federal do Paraná. Curitiba, 2002. 68 p.

5 MAZZA, V.A. A comunicação não-verbal como forma de cuidado de enfermagem: ensino e prática. Dissertação (Mestrado em Enfermagem). Curso de Pós Graduação em Enfermagem, Universidade Federal de Santa Catarina. Curitiba, 1998. 70 p.

6 PARANÁ. Lei $\mathbf{n} .^{\circ} 8627$ de 9 de dezembro de 1987. Torna obrigatória a realização do "Teste do Pezinho" no Estado do Paraná. Curitiba, 1987.

Endereço da autora:

Rua da Capitania, 286 81520-590 - Curitiba - PR E-mail: marlymarton@hotmail.com 